\title{
Bisphosphonate-Associated Osteonecrosis of the Jaw: Are We Dealing with a Localized Non-Traditional Calciphylaxis?
}

\author{
Meiller $\mathrm{TF}^{1,2,}$ Almubarak $\mathrm{H}^{2}$, Weikel $\mathrm{DS}^{1,2}$, Brahim $\mathrm{J}^{1,3}$ and Scheper $\mathrm{MA}^{1,2, *}$ \\ ${ }^{I}$ Marlene and Stewart Greenebaum Cancer Center, University of Maryland Medical Center, Baltimore, USA \\ ${ }^{2}$ Department of Oncology and Diagnostic Sciences, University of Maryland, Baltimore, USA \\ ${ }^{3}$ Department of Oral and Maxillofacial Surgery, University of Maryland, Baltimore, USA
}

\begin{abstract}
The bisphosphonate (BP) family of drugs has been used as a vital component in cancer therapy and many other diseases. One of the main adverse effects related to (BP) is BP-associated osteonecrosis of the jaw (ONJ). Although this condition was first recognized in 2003, the pathophysiologic mechanism remains undefined. Our hypothesis is that ONJs clinical course and delayed wound healing is in part correlated to a localized non-traditional calciphylaxis. This effect is identified by the evidence of calcium deposition in the connective tissue and around small blood vessels in the soft tissues immediately adjacent to ONJ lesions. This phenomenon helps to fill gaps in the cascade of events which leads to soft tissue ischemia, necrosis, and non-healing ONJ lesions. Our finding adds to the current knowledge of the potential pathophysiologic mechanisms related to ONJ.
\end{abstract}

Keywords: Bisphosphonate, bisphosphonate-associated osteonecrosis of the jaw, calciphylaxis, oncology, onj, therapeutic complications.

\section{INTRODUCTION}

Every year, an estimated 24 million bisphosphonate (BP) prescriptions are written in the U.S. alone [1]. One of the more recently reported serious adverse effects of BP treatment is BP-associated osteonecrosis of the jaw (ONJ). This condition was first recognized in 2003 and is predicted to occur in up to $28 \%$ of IV BP patients, with an estimated weighted prevalence of $13.3 \%$ in studies with accurate follow-up [2].

Currently, ONJ lacks a defined pathophysiologic mechanism. Unfortunately, researchers initially ignored the cross talk between bone and oral mucosal soft tissue, as this condition is truly a chemonecrosis process. Recently, we investigated an oral soft tissue mechanism as a potential contributor to the initiation of ONJ and more importantly, an inhibitor of wound healing, secondary to free BP [3-5]. Now we add to this hypothesis, a potentially distinct and complementary mechanism of initiation and persistence of ONJ, secondary to a local non-traditional calciphylaxis through vascular and soft tissue calcium deposition [6] (Fig. 1).

\section{MATERIAL AND METHODS}

We reviewed the tissue archives of the University of Maryland, Baltimore, Oral Pathology Consultants from 2003 to 2011 (with IRB approval) and found 10 cases of diagnosed ONJ which contained adjacent soft tissue. Paraffin embedded tissue sections from these 10 stage 3 (AAOMS)

*Address correspondence to this author at the $650 \mathrm{~W}$ Baltimore Street, $7 \mathrm{~N}$, Room 2756 Baltimore, MD 21201, USA; Tel: (410)-706-7936; Fax: (410)706-0519; E-mail: mscheper@umaryland.edu
ONJs in cancer patients using zoledronic acid (bone and adjacent soft tissue), were first evaluated using hematoxylin and eosin stain for accurate diagnosis. Next, unstained sections were deparaffinized, immersed in ethanol $100 \%$ and $95 \%$, washed with distilled $\mathrm{H} 2 \mathrm{O}$ and incubated with $1 \%$ silver nitrate solution under UV light for 2 hours. The sections were then washed with distilled $\mathrm{H} 2 \mathrm{O}$ and 5\% sodium thiosulfate for 5 minutes. Next the sections were counterstained with nuclear fast red for 5 minutes. As a negative control, sections were treated with phosphate-buffered saline with omission of the von Kossa stain. Additionally, five normal archived oral mucosal tissues were used as a control. The von Kossa staining was reviewed by two independent, certified Oral Pathologists (MS and NB).

\section{RESULTS}

Using von Kossa staining, we demonstrated the presence of calcium in 8 of the $10 \mathrm{ONJ}$ cases within the connective tissue and surrounding blood vessels. (Fig. 1A, B) All of these cases demonstrated a significant delay in ONJ wound healing. The bone within these specimens also demonstrated the presence of calcium at their leading edge where BP would typically bind to calcium phosphate since they are considered analogs of pyrophosphate [7] (Fig. 1C). Five normal archived oral mucosal tissues were used as a control. (Fig. 1D).

\section{DISCUSSION}

Calciphylaxis is classically defined as a multifactorial renal phenomenon, whereby microcalcification of small blood vessels leads to soft tissue ischemia, necrosis and nonhealing lesions [6]. This classic presentation is frequently 

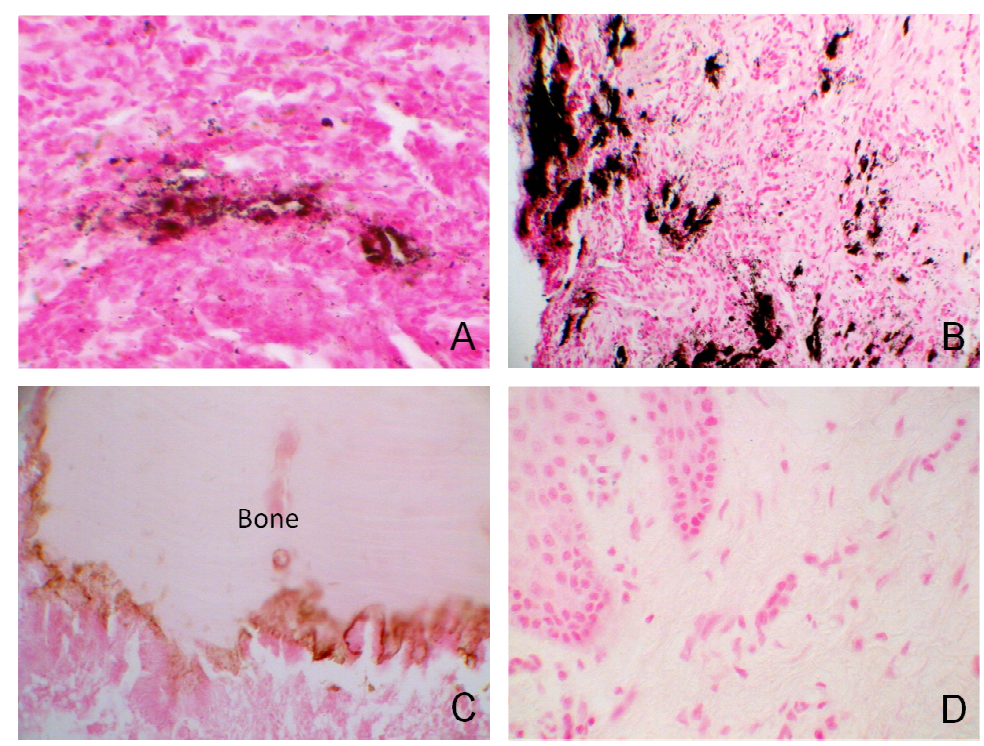

Fig. (1). ONJ cases with adjacent soft tissue were stained for calcium using von Kossa. A, B: ONJ staining for calcium positive in 8 of 10 cases around vessels and in the connective tissue (black/brown). C: Bone showing calcium staining at the leading edge. D: Normal oral mucosa control (A, C, D 400x/ B 200X).

fatal and is seen most often at end-stage renal failure [8]. However, in certain hypercalcemic states, such as malignancy (Breast and Multiple Myeloma), hyperparathyroidism, cirrhosis, Crohns and collagen disease conditions, a nonuremic non-traditional calciphylaxis is shown to induce vascular and tissue deposition of calcium in the submucosal tissues [6-12]. This complication must surpass a critical threshold of sensitizing conditions (e.g. hypercalcemia and inflammation of malignancy; and BP and corticosteroid use) and thrombogenic stimuli (e.g. dental trauma). Since the mandible is a primary site for BP saturation and is commonly affected by trauma, infection and inflammation; an acidic microenvironment would release free BP from bone and secondarily release calcium from its BP bound state to induce oral mucosal apoptosis/necrosis $[4,7,13,14]$.

Clinically, ONJ is observed as a mucosal dehiscence leading to the formation of a superficial mucosal ulcer, which continues to extend with time and results in detectable bone exposure, necrosis and sequestration. Moreover, like calciphylaxis, these lesions typically present as non-healing wounds treated empirically. Once a lesion occurs, there is tremendous difficulty in treating these lesions, which leads to delayed or refusal of dental treatment and discontinuation of necessary cancer therapy. Currently, the only therapeutic regimen is antimicrobial therapy, with surgical interventions reserved only for severe cases. Therefore, a tetralogical cascade must exist, including a combination of effects on bone, vasculature, microbial biofilm and oral mucosal soft tissues, especially in wound healing.

\section{CONCLUSION}

Part of the treatment regimen for calciphylaxis includes antibiotics and rebalancing calcium and phosphate, while avoiding local tissue trauma, similar to ONJ. Interestingly, the standard therapeutic regimen for ONJ, amoxicillin, is not affected by calcium and appears to have better success than tetracyclines which lose activity in the context of high calcium levels. Perhaps balancing the calcium and phosphate levels, and creating a neutral $\mathrm{pH}$, along with the standard of care therapy of eliminating the bacterial load, may become a translational model for investigating potential pathogenesis directed therapeutics.

\section{CONFLICT OF INTEREST}

The authors declare that they have no competing interests.

\section{ACKNOWLEDGEMENTS}

Grant: Supported by K12RR023250.

\section{REFERENCES}

[1] Knight RJ, Reddy C, Rtshiladze MA, Lvoff G, Sherring D, Marussi D. Bisphosphonate-related osteonecrosis of the jaw: tip of the iceberg. J Craniofac Surg 2010; 21: 25-32.

[2] Migliorati CA, Woo SB, Hewson I, et al. A systematic review of bisphosphonate osteonecrosis (BON) in cancer. Support Care Cancer 2010; 18: 1099-106.

[3] Scheper M, Chaisuparat R, Cullen K, Meiller T. A novel soft-tissue in vitro model for bisphosphonate-associated osteonecrosis. Fibrogenesis Tissue Repair 2010; 3: 6.

[4] Scheper MA, Badros A, Chaisuparat R, Cullen KJ, Meiller TF. Effect of zoledronic acid on oral fibroblasts and epithelial cells: a potential mechanism of bisphosphonate-associated osteonecrosis. Br J Haematol 2009; 144: 667-76.

[5] Scheper MA, Badros A, Salama AR, et al. A novel bioassay model to determine clinically significant bisphosphonate levels. Support Care Cancer 2009; 17(12): 1553-7.

[6] Wilmer WA, Magro CM. Calciphylaxis: emerging concepts in prevention, diagnosis, and treatment. Semin Dial 2002; 15:172-86.

[7] Li B, Ling Chau JF, Wang X, Leong WF. Bisphosphonates, specific inhibitors of osteoclast function and a class of drugs for osteoporosis therapy. J Cell Biochem 2011; 112: 1229-42.

[8] Sullivan E, Hoyle C. Calciphylaxis, occurring 10 weeks after hypercalcaemia, in a patient with multiple myeloma. Br J Haematol 2011; 155(2): 136.

[9] Kalajian AH, Malhotra PS, Callen JP, Parker LP. Calciphylaxis with normal renal and parathyroid function: not as rare as previously believed. Arch Dermatol 2009;145: 451-8.

[10] Padovan C, Bonfigli F, Ulessi B, Gottardi C, Giansante C, Trevisan G. Calciphylaxis of the breast: a rare disease in the differential diagnosis of breast cancer. Acta Dermatovenerol Croat 2008; 16: 83-6. 
[11] Crippa C, Ferrari S, Drera M, et al. Pulmonary calciphylaxis and metastatic calcification with acute respiratory failure in multiple myeloma. J Clin Oncol 2010; 28: e133-5.

[12] Nigwekar SU, Wolf M, Sterns RH, Hix JK. Calciphylaxis from nonuremic causes:a systematic review. Clin J Am Soc Nephrol 2008; 3: 1139-43.
[13] Otto S, Pautke C, Opelz C, et al. Osteonecrosis of the jaw: effect of bisphosphonate type, local concentration, and acidic milieu on the pathomechanism. J Oral Maxillofac Surg 2010; 68: 2837-45.

[14] Kozloff KM, Volakis LI, Marini JC, Caird MS. Near-infrared fluorescent probe traces bisphosphonate delivery and retention in vivo. J Bone Miner Res 2010; 25:1748-58.

Received: October 15, 2011

Revised: November 21, 2011

Accepted: November 22, 2011

(C) Meiller et al.; Licensee Bentham Open .

This is an open access article licensed under the terms of the Creative Commons Attribution Non-Commercial License (http://creativecommons.org/ licenses/by-nc/3.0/) which permits unrestricted, non-commercial use, distribution and reproduction in any medium, provided the work is properly cited. 